\title{
Separation of the Climatic and Land Cover Impacts on the Flow Regime Changes in Two Watersheds of Northeastern Tibetan Plateau
}

\author{
Linshan Yang, 1,2 Qi Feng, ${ }^{1}$ Zhenliang Yin, ${ }^{1}$ Ravinesh C. Deo, ${ }^{1,3}$ Xiaohu Wen, \\ Jianhua $\mathrm{Si}^{1}{ }^{1}$ and Changbin $\mathrm{Li}^{4}$ \\ ${ }^{1}$ Key Laboratory of Ecohydrology of Inland River Basin, Northwest Institute of Eco-Environment and Resources, \\ Chinese Academy of Sciences, Lanzhou, Gansu 730000, China \\ ${ }^{2}$ University of Chinese Academy of Sciences, Beijing 100049, China \\ ${ }^{3}$ School of Agricultural, Computational and Environmental Sciences, Institute of Agriculture and Environment, \\ University of Southern Queensland, Springfield, QLD 4300, Australia \\ ${ }^{4}$ College of Earth Environmental Sciences, Lanzhou University, Lanzhou, Gansu 730000, China
}

Correspondence should be addressed to Qi Feng; qifeng@lzb.ac.cn

Received 20 April 2017; Revised 4 July 2017; Accepted 6 August 2017; Published 26 September 2017

Academic Editor: Francesco Viola

Copyright (C) 2017 Linshan Yang et al. This is an open access article distributed under the Creative Commons Attribution License, which permits unrestricted use, distribution, and reproduction in any medium, provided the original work is properly cited.

\begin{abstract}
Assessment of the effects of climate change and land use/cover change (LUCC) on the flow regimes in watershed regions is a fundamental research need in terms of the sustainable water resources management and ecosocial developments. In this study, a statistical and modeling integrated method utilizing the Soil and Water Assessment Tool (SWAT) has been adopted in two watersheds of northeastern Tibetan Plateau to separate the individual impacts of climate and LUCC on the flow regime metrics. The integrated effects of both LUCC and climate change have led to an increase in the annual streamflow in the Yingluoxia catchment (YLC) region and a decline in the Minxian catchment (MXC) region by 3.2\% and $4.3 \%$ of their total streamflow, respectively. Climate change has shown an increase in streamflow in YLC and a decline in MXC region, occupying $107.3 \%$ and $93.75 \%$ of the total streamflow changes, respectively, a reflection of climatic latitude effect on streamflow. It is thus construed that the climatic factors contribute to more significant influence than LUCC on the magnitude, variability, duration, and component of the flow regimes, implying that the climate certainly dominates the flow regime changes in northeastern Tibetan Plateau.
\end{abstract}

\section{Introduction}

Climate change and land use/cover change (LUCC) are overlapped factors and function as two critical drivers that directly influence hydrological processes in various watersheds $[1,2]$. This is especially true in arid and semiarid areas, where the ecosystems are fragile and more sensitive to climate change due to the restricted availability of water supply. Researchers have thus dedicated significant efforts towards broadening the understanding of the influence of these two variables on hydrological processes, as well as on the flow regimes [3]. As it is well-known, the increase in the concentration of the greenhouse gases emission is causing global climatic warming [4]. Consequently, the temporal spatial distribution and the magnitude of precipitation, frequency, and intensity of floods and recharge and discharge of streamflow are likely to be altered accordingly [5]. LUCC can alter the associations of streamflow generation, transpiration, interception, and ecosystem conservation $[6,7]$. Deforestation, for instance, can produce higher streamflow generation and reduce lag time between precipitation and runoff leading to increase in peak flow, flood damage risks, and severe soil erosion $[8,9]$. Conversely, reforestation and intensive agriculture rehabilitation can dramatically decrease the generation of streamflow and trigger an increase in the flow concentration time. Although several sources in literature have reported the interactions of forest change, climate, and hydrological activities [10], how these factors are incorporated into hydrological processes as well as the different flow regimes still remain unclear. It is thus important to gather further insights into 
the impacts of the climate and LUCC factors on the flow regimes in order to accurately quantify their respective roles in different watershed regions.

Available hydrological impact assessment methods commonly used in literature include the catchment paired experiments, statistics analysis, and measurements with hydrological models [11], but seldom have these been involved in streamflow regime studies $[12,13]$. Moreover, the experimental and statistical methods treat the study basin as a black box and rarely examined the complexities of precipitation changes, underlying surface conditions, and the interactions between climate change and the respective hydrological processes [2]. Hydrological models, however, offer a viable framework for conceptualizing and investigating the relationships between climate, underlying surface, and hydrological processes in various categories of time and space $[14,15]$ and the approach of one-factor-at-a-time (OFAT) has been widely applied [16, 17]. For instance, Karlsson et al. [18] modeled the combined effects of land use and climate changes on the hydrology for a catchment located in Denmark. Zhao et al. [19] evaluated the climate variability and land use influences on green and blue water resource in Weihe River basin, NW China. These methods considered the hydrological processes and their interactions with the environment. It should be noted that hydrological models are more effective as they relate the model parameters directly to the physically observable land surface characteristics [20]. However, the assumption within OFAT method is that in the course of evaluating the influence of a given factor on hydrological processes, the other factors' effects are not considered. In fact, the other factors not considered are changing concurrently over the entire period of observation which can contribute as an apparent bias in the separation results. Separation of the individual influence of the two factors on hydrological processes thus warrants the need for inputting the applicable status of two factors from the baseline period to the entire period. Yang et al. [21] recommended that a combined statistical and modeling method could be used to resolve this bias and further identified the climate and land cover change impacts on the hydrological processes in the Heihe River. In that study, the results were more reasonable and offered greater accuracy than the traditional OFAT and other statistical methods.

The Yingluoxia catchment (YLC) and Minxian catchment (MXC), utilized in this study, are situated in the northeastern Tibetan Plateau, which are primarily influenced by the northern hemispheric middle latitude Westerlies and the Asia summer monsoon, respectively $[22,23]$. The two watersheds are nearly located at the same longitude, but quietly different latitude. It means the further north the watersheds, the less the water vapor content received. Meanwhile, these regions are among the most sensitive zones in terms of climate change [24]. More than 1.3 million people and 266,000 ha of irrigated agricultural land rely on the streamflow from YLC region [25]. This flow is crucial for maintaining the oasis and agricultural ecosystems [26, 27]. The MXC is considered as an important water resource hub for the Yellow River, but it is also a source region addressing serious water shortage area in the Gansu Loess Plateau [28]. Therefore, the quantification of the impacts of climate change and LUCC on flow regimes in these regions is crucial in order to clarify the hydrological response to different climate types and understand the flow regime behaviors with different climate and land cover combinations. The objectives of this study are, thus, (1) to define a conceptual framework and to propose a modified OFAT method for separating the individual contribution of climate and LUCC to flow regimes, (2) to improve the separation accuracy and to compare the separation results with climatic conditions, and (3) to compare and gain further insights and understand the effects of the two major factors on streamflow. The results can provide a beneficial reference for an assessment and proper management of the water resources for the associated policymakers and stakeholders within the YLC and MXC regions.

\section{Study Area and Data Collection}

\subsection{Study Area}

2.1.1. The Yingluoxia Catchment (YLC). YLC, the headwater region of the Heihe River basin, is located in the middle of the Hexi Corridor, China, with a total drainage area of $10,009 \mathrm{~km}^{2}$ lying between $99^{\circ}$ and $101^{\circ} \mathrm{E}$ and $38^{\circ}$ and $39^{\circ} \mathrm{N}$. The elevation varies from $5058 \mathrm{~m}$ to $1668 \mathrm{~m}$ (Figure 1). YLC is the main region for the generation of streamflow in the entire basin. Approximately $90 \%$ of the water resources in the middle and lower reaches are therefore recharged by the streamflow from the YLC region. The climate, mainly controlled by the northern hemispheric middle latitude Westerlies, is characterized as cold and moist with large spatial and temporal heterogeneity [29]. The average annual precipitation is more than $400 \mathrm{~mm}$ and increases by $15.5-16.4 \mathrm{~mm}$ for every $100 \mathrm{~m}$ increase in the elevation. Nearly $70 \%$ of annual precipitation occurs from June to September and less than $10 \%$ from November to March. The annual average air temperature varies from $-5^{\circ} \mathrm{C}$ to $4^{\circ} \mathrm{C}$, and decreases $0.5^{\circ} \mathrm{C}$ along with the elevation increase for every $100 \mathrm{~m} \mathrm{[30].} \mathrm{The} \mathrm{total} \mathrm{annual}$ runoff is $16.05 \times 10^{8} \mathrm{~m}^{3}$ with significant interannual variability [31]. Conditions within the Heihe River have attracted great attention in China due to increasing pressures in the nation, particularly in water resources and the degradation of natural environmental sectors $[32,33]$.

2.1.2. The Minxian Catchment (MXC). MXC, the headwater of the Taohe River, is covered by a total drainage area of $14,912 \mathrm{~km}^{2}$ with an annual streamflow of $26.8 \times 10^{8} \mathrm{~m}^{3}$, lying between $101^{\circ}$ and $105^{\circ} \mathrm{E}$ and $34^{\circ}$ and $35^{\circ} \mathrm{N}$, dominated by the Asia summer monsoon. The land cover and topography change from forests and mountains to grasslands and open valleys [28]. The annual average air temperature increases from 1 to $6^{\circ} \mathrm{C}$ at elevations ranging from 4562 to $2,411 \mathrm{~m}$. The mean annual precipitation decreases from 640 to $560 \mathrm{~mm}$ from west to east of MXC region. The dominant climate varies from an alpine cold humid and subhumid climate to a temperate semiarid climate, and the terrestrial vegetation ranges from alpine grasslands and forest to arid grasslands and rain-fed cultivated lands [34]. 


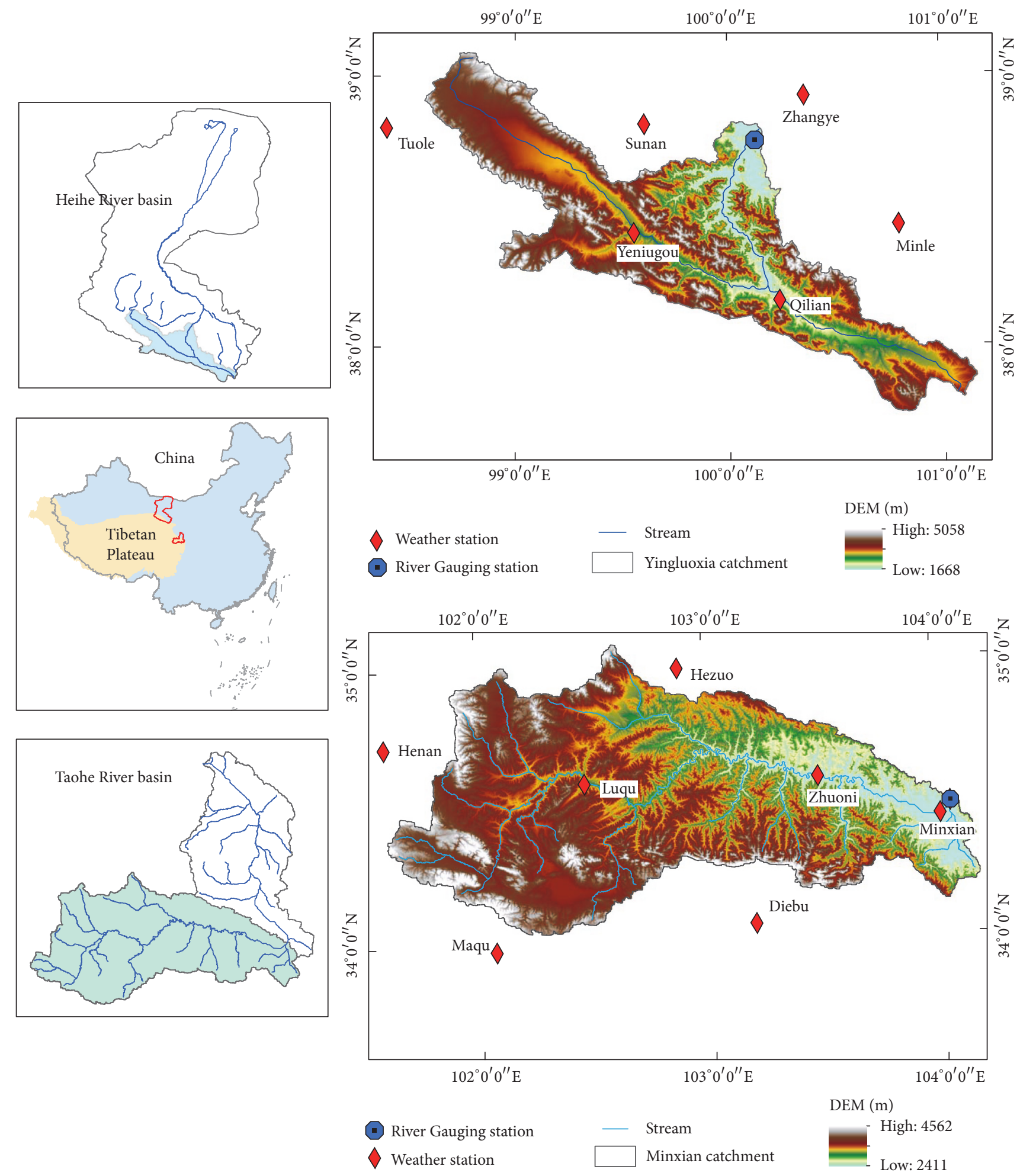

FIGURE 1: Location of Yingluoxia catchment (YLC) and Minxian catchment (MXC) together with distribution of digital elevation model and hydrometeorology stations.

2.2. Data Collection. The digital elevation model (DEM) $(30 \mathrm{~m} \times 30 \mathrm{~m})$, map of soil types $(1: 1000000)$, and land use maps $(100 \mathrm{~m} \times 100 \mathrm{~m})$ of $1980 \mathrm{~s}$ and $2000 \mathrm{~s}$ were collected for SWAT modeling. Soil properties were obtained from the Chinese Soil Database of the Institute of Soil Science, while land use properties were also sourced directly from the SWAT model database. Surface runoff data were received from the Scientific Database of the Yellow River Hydrology Service, which included the monthly time series from 1980 to 2010 and the meteorological data were collected from the China 
TABLE 1: The flow regime metrics selected to describe streamflow paradigm.

\begin{tabular}{lcccc}
\hline Number & Groups & Flow regimes & Hydrological metrics & Abbreviation \\
\hline 1 & & Average flow & Average monthly flow & MMF \\
2 & Magnitude & Low-flow & Low monthly flow (75th percentile) & Lw75 \\
3 & & High-flow & High monthly flow (25th percentile) & Hg25 \\
4 & Variability & Average flow & Coefficient of variation of monthly flow & CvMF \\
5 & Duration & Median flow & Time exceeded of median flow & DMF \\
6 & Component & Base flow & Base flow index & BFI \\
\hline
\end{tabular}

Meteorological Administration. The latter source provided crucial information on the daily precipitation, maximum and minimum temperature, sunshine hours, humidity, and wind speed. The long term measured gauge air temperature and precipitation were thus aggregated to determine their monthly values by using the daily datasets. In terms of data quality control, the homogenization of climate and streamflow data has been tested using the standard normal homogeneity test.

\section{Methodologies}

3.1. Flow Regime Metrics. Six representative streamflow regimes metrics, comprised of the flow magnitudes (MMF, Lw75, and Hg25), variability (CvMF), duration (DMF), and component, were selected to evaluate indices of the impacts of climate change and LUCC on streamflow (Table 1) $[25,35]$. It is noteworthy that the base flow index (BFI) is the fraction of the base flow over the total streamflow [16], which is contributed by the groundwater. We have used BFI to reflect the low-flow characteristic of the streamflow component. Due to the restrictions by the simulation performance of the long term daily flow regimes in our study area, it was impossible to describe the fine-detail characteristics of daily flow regimes. Monthly flow metrics would thus be a valid alternative, and this has been widely used in the present water management strategies. However, the monthly flow regime could still capture several characteristics of daily flow regimes [36].

3.2. SWAT Model. SWAT is a physically and mathematically based hydrological model developed by the research centers at US Department of Agriculture [37]. The model requires significant quantities of specialized information, including weather, soil properties, topography, vegetation, and land management practices. The resulting data is used to determine parameters controlling hydrological processes in a given watershed. A detailed description of the model and its input/output variables can be found in the model's public domain website at http://www.brc.tamus.edu/swat.

SWAT processes hydrological simulation by applying the principle of water balance in each of the hydrologic response units (HRUs) [38], which define areas with identical combinations of surface slope, land use, and soil type [18]. The water balance equation is given as

$$
\mathrm{SW}_{t}=\mathrm{SW}_{0}+\sum_{i=1}^{t}\left(P_{\text {day }}-Q_{\text {surf }}-E_{a}-W_{\text {seep }}-Q_{\mathrm{gw}}\right),
$$

where $\mathrm{SW}_{t}$ is the final soil moisture $(\mathrm{mm}), \mathrm{SW}_{0}$ is the initial soil moisture at the time of $i(\mathrm{~mm}), P_{\text {day }}$ is the precipitation at the time of $i(\mathrm{~mm}), Q_{\text {surf }}$ is the streamflow at the time of $i(\mathrm{~mm}), E_{a}$ is evapotranspiration at the time of $i(\mathrm{~mm})$, $W_{\text {seep }}$ is the water flow to the unsaturated zone from the soil profile at the time of $i(\mathrm{~mm})$, and $Q_{\mathrm{gw}}$ is the water flow from the watershed from underground at the time of $i(\mathrm{~mm})$. In this study the SCS (Soil Conservation Service) curve number method is applied for computing streamflow volume. The Muskingum and Penman-Monteith methods are used for flow routing and estimating the potential evapotranspiration.

\subsection{Framework for Separating the Effects of Climate Change} and LUCC. In a given river basin, the changes in hydrological processes are caused by climate change and LUCC, both of which are assumed to be independent factors [39]. In this study, the hydrological regimes are treated as a function of these two factors. To separate the discrete effects of climate change on the flow regime, we have created a schematic in order to illustrate the variation in hydrological processes along with climate change under differing LUCC scenarios (Figure 2).

Due to the different response relationships between different land cover and hydrological processes, we show the schematic of flow regimes response to land covers $L_{1}$ and $L_{2}$ (Figure 2). Note that $\Delta Q_{C 1}$ and $\Delta Q_{C 2}$ are the responses of flow regimes to the climate change $(\Delta C)$ under land cover conditions $L_{1}$ and $L_{2}$. Normally, $\Delta Q_{C 1}$ and $\Delta Q_{C 2}$ are different, when the land cover change $(\Delta L)$ is smaller, $\Delta Q_{C 1}$ is closer to $\Delta Q_{C 2}$. Thus, we use the average of $\Delta Q_{C 1}$ and $\Delta Q_{C 2}$ to denote separate impacts of climate change on hydrological elements $\left(\Delta Q_{C}\right)$ :

$$
\begin{aligned}
\Delta Q_{C} & =\frac{1}{2}\left(\Delta Q_{C 1}+\Delta Q_{C 2}\right) \\
& =\frac{1}{2}\left[\left(Q_{C 2}^{L 1}-Q_{C 1}^{L 1}\right)+\left(Q_{C 2}^{L 2}-Q_{C 1}^{L 2}\right)\right],
\end{aligned}
$$

where $Q_{C 1}^{L 1}, Q_{C 1}^{L 2}, Q_{C 2}^{L 1}$, and $Q_{C 2}^{L 2}$ donate the flow regimes value at points $\mathbf{A}, \mathbf{B}, \mathbf{C}$, and $\mathbf{D}$, respectively. Similarly, the responses of flow regime to LUCC are calculated by applying difference of hydrological component values of land use conditions $L_{1}$ and $L_{2}$ under the climate condition of $C_{1}$ and $C_{2}$, denoted as $\Delta Q_{L 1}$ and $\Delta Q_{L 2}$, respectively. The smaller the change in climate change $(\Delta C)$, the closer $\Delta Q_{L 1}$ is to $\Delta Q_{L 2}$. Thus, we 
TABLE 2: Performance assessments of the SWAT model in the two watersheds.

\begin{tabular}{|c|c|c|c|c|c|c|}
\hline \multirow{2}{*}{ Watershed } & \multirow{2}{*}{ Period } & \multicolumn{2}{|c|}{$R$} & \multicolumn{2}{|c|}{ NSE } & \multirow{2}{*}{ BIAS } \\
\hline & & Monthly & Yearly & Monthly & Yearly & \\
\hline \multirow{2}{*}{ YLC } & Calibration (1982-1995) & 0.95 & 0.94 & 0.91 & 0.88 & $1.14 \%$ \\
\hline & Validation (1996-2010) & 0.96 & 0.96 & 0.90 & 0.76 & $-0.15 \%$ \\
\hline \multirow{2}{*}{ MXC } & Calibration (1982-1995) & 0.90 & 0.91 & 0.85 & 0.80 & $6.80 \%$ \\
\hline & Validation (1996-2010) & 0.94 & 0.96 & 0.74 & 0.78 & $2.70 \%$ \\
\hline
\end{tabular}

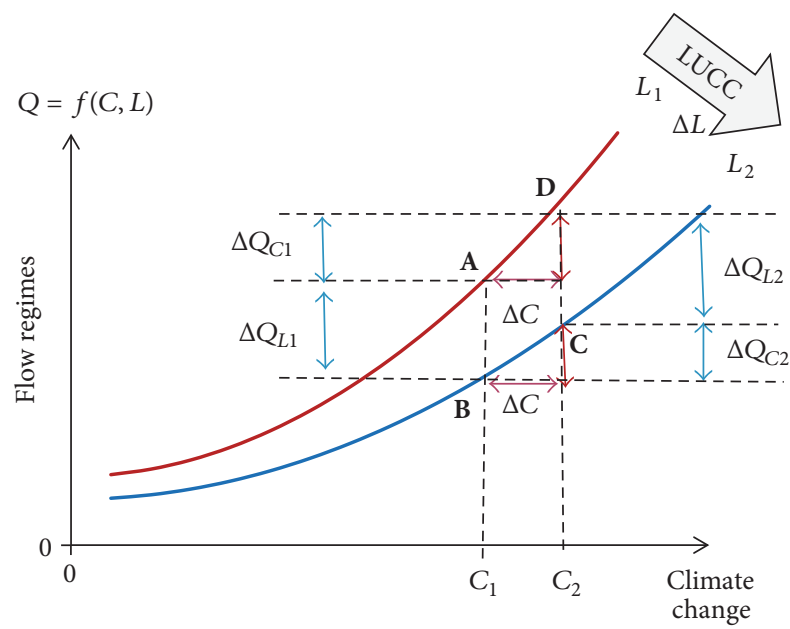

FIGURE 2: Schematic for separating the contribution of climate change and LUCC to flow regimes.

accept the arithmetic mean of $\Delta Q_{L 1}$ and $\Delta Q_{L 2}$ as the separate impact of LUCC to hydrological elements $\left(\Delta Q_{L}\right)$ as

$$
\begin{aligned}
\Delta Q_{L} & =\frac{1}{2}\left(\Delta Q_{L 1}+\Delta Q_{L 2}\right) \\
& =\frac{1}{2}\left[\left(Q_{C 1}^{L 2}-Q_{C 1}^{L 1}\right)+\left(Q_{C 2}^{L 2}-Q_{C 2}^{L 1}\right)\right] .
\end{aligned}
$$

The total change in hydrological element $\Delta Q$ equals the sum of the two factors contributions. The total change also can be estimated by the differences of the hydrological elements in the two periods, as

$$
\Delta Q=\Delta Q_{L}+\Delta Q_{C}=Q_{C 2}^{L 2}-Q_{C 1}^{L 1},
$$

where $\Delta Q$ represents the total change of a given hydrological element; hydrological elements can serve as statistic mean values over annual, seasonal, or monthly time scales [21].

In this study, we select the period 1982-1995 as baseline situation and 1996-2010 as affection period, along with land use for each period reflected on a separate map. The land use map for the 1980s and 2000s is used to represent the land use patterns for the two periods. A calibrated SWAT model is then applied to each of the four permutations derived from the two time periods and the two land use maps; hereinafter these are referred to as four scenarios. The influences of the LUCC and climate change are quantified by comparing the
SWAT outputs of the four scenarios by using the separation equations ((2) and (3)), as follows:

(S1) 1980s land use and 1982-1995 climate

(S2) 2000s land use and 1982-1995 climate

(S3) 1980s land use and 1996-2010 climate

(S4) 2000s land use and 1996-2010 climate.

3.4. Model Calibration and Validation. The SWAT model is calibrated using historical data from January 1982 to December 1995. The validation period is based on the observed runoff from January 1996 to December 2010. And the warming up period is January 1980 to December 1981. Correlation coefficient $(R)$, Nash-Sutcliffe coefficient (NSE), and Relative Bias (BIAS) are used to evaluate the performance of SWAT during calibration and validation [40, 41]. The equations are defined as

$$
\begin{aligned}
& R=\frac{\sum_{i=1}^{N}\left(Q_{\mathrm{obs}}(i)-\bar{Q}_{\mathrm{obs}}\right)\left(Q_{\mathrm{sim}}(i)-\bar{Q}_{\mathrm{sim}}\right)}{\left[\sum_{i=1}^{N}\left(Q_{\mathrm{obs}}(i)-\bar{Q}_{\mathrm{obs}}\right)^{2}\right]^{1 / 2}\left[\sum_{i=1}^{N}\left(Q_{\mathrm{sim}}(i)-\bar{Q}_{\mathrm{sim}}\right)^{2}\right]^{1 / 2}}, \\
& \mathrm{BIAS}=\frac{\sum_{i=1}^{N}\left(Q_{\mathrm{obs}}(i)-Q_{\mathrm{sim}}(i)\right)}{\sum_{i=1}^{N} Q_{\mathrm{obs}}(i)} \times 100 \%, \\
& \mathrm{NSE}=1-\frac{\sum_{i=1}^{N}\left(Q_{\mathrm{obs}}(i)-Q_{\text {sim }}(i)\right)^{2}}{\sum_{i=1}^{N}\left(Q_{\mathrm{obs}}(i)-\bar{Q}_{\mathrm{obs}}\right)^{2}},
\end{aligned}
$$

where $N$ is the number of data points, $Q_{\mathrm{obs}}$ is the observed runoff, $Q_{\text {sim }}$ is the simulated runoff, and $\bar{Q}_{\text {obs }}$ and $\bar{Q}_{\text {sim }}$ are the mean values of the observed and simulated runoff, respectively. Model performance is considered satisfactory if NSE is greater than 0.5 and BIAS is less than 25\% [42].

\section{Results and Discussion}

4.1. Calibration and Validation of SWAT Model. The simulated monthly streamflow has good correspondence to the observed series during calibration and validation (Figure 3). In accordance with Table 2 and Figure 4, there exist significant correlations between the observed and simulated streamflow at monthly and annual scales. That is, the BIAS is found to be approximately $1.14 \%$ and $6.80 \%$ for the calibration and $-0.15 \%$ and $2.7 \%$ for the validation period in the YLC and MXC regions, respectively. The correlation coefficient in the 


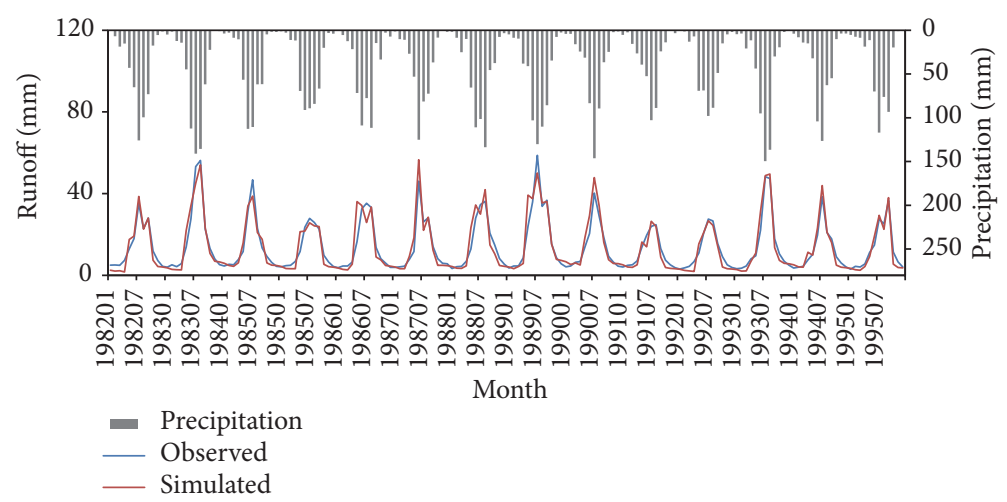

(a)

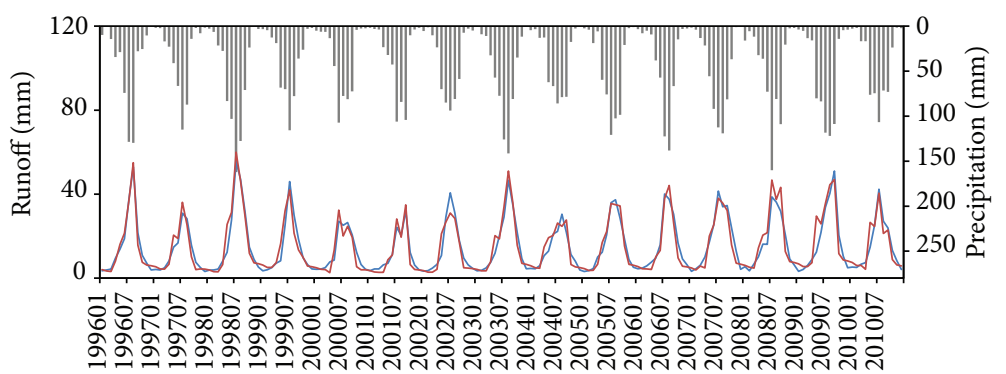

Month

- Precipitation

— Observed

— Simulated

(b)

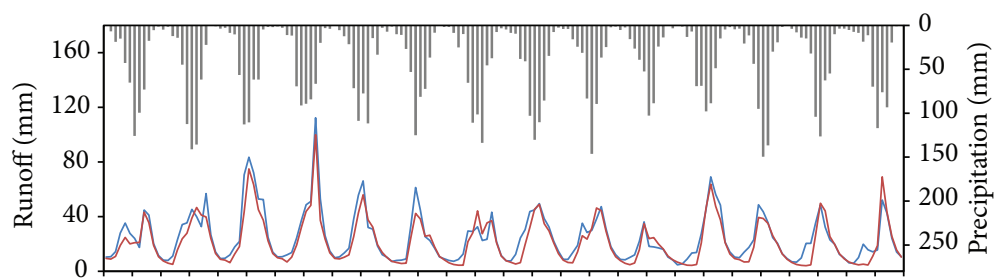

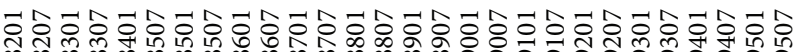

o.

Month

- Precipitation

- Observed

— Simulated

(c)

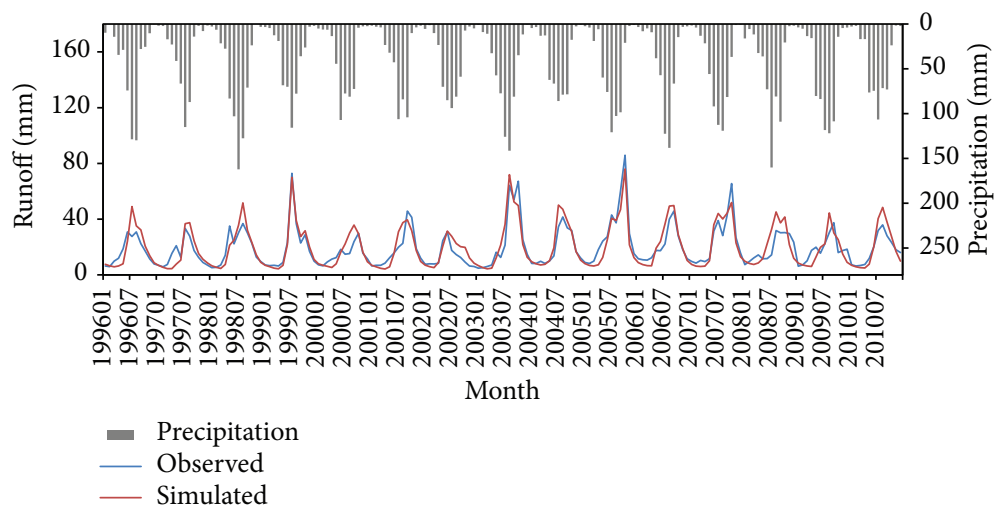

(d)

FIGURE 3: Simulated and observed monthly runoff variation in YLC during (a) calibration and (b) validation and in MXC during (c) calibration and (d) validation. 

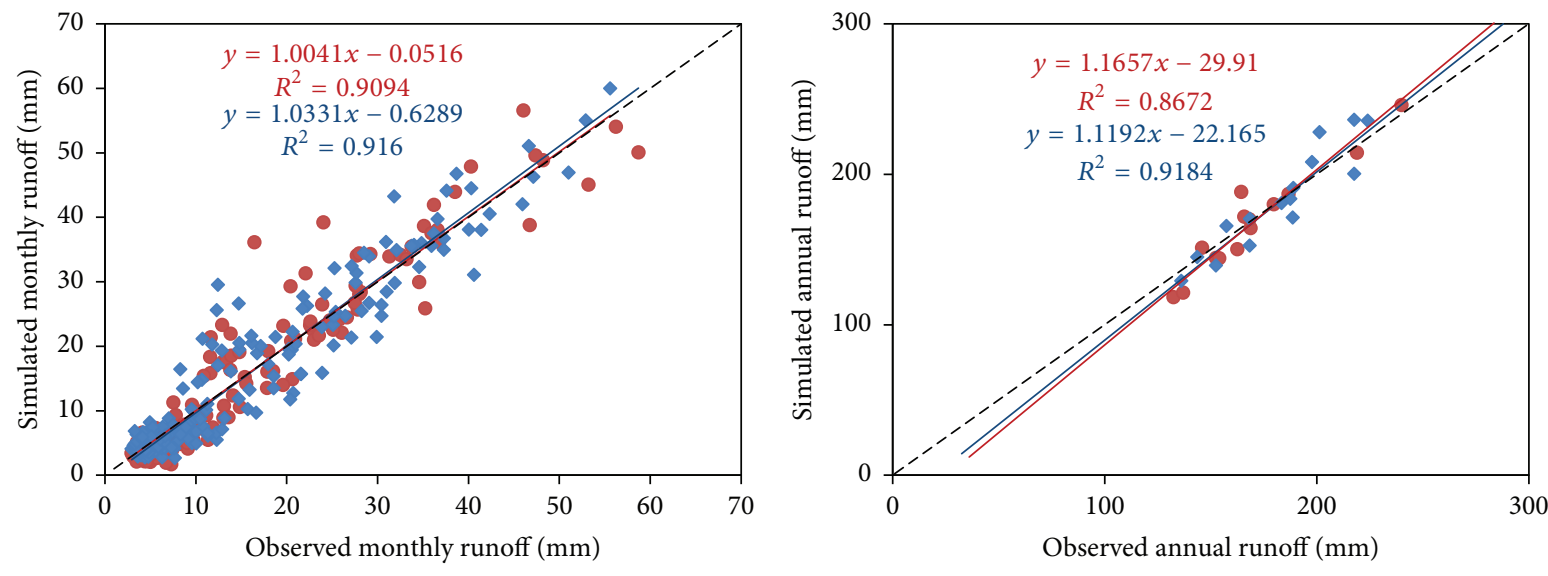

- Calibration

- Validation

--- $1: 1$ line

(a)

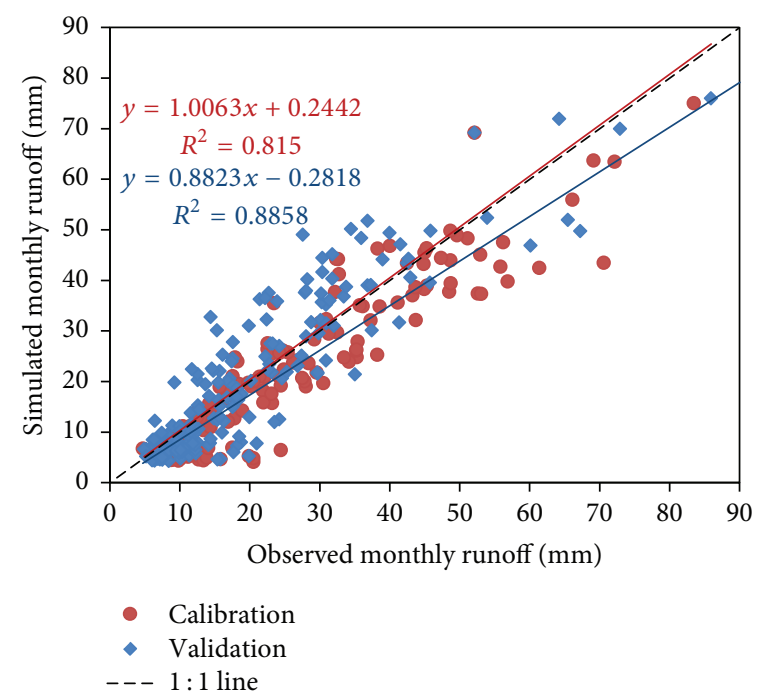

(c)

(b)

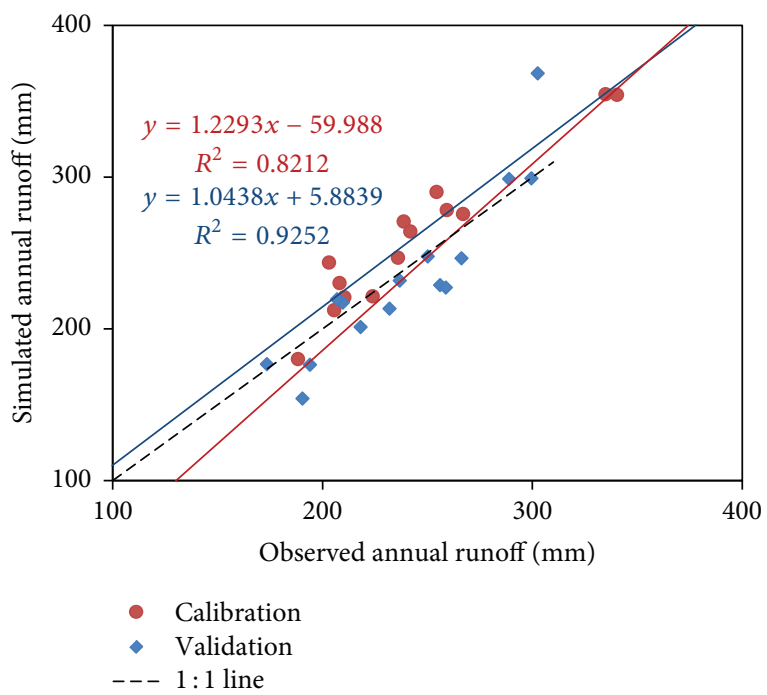

(d)

FIGURE 4: Scatter plots of observed and simulated runoff in YLC at (a) monthly and (b) annual scales and in MXC at (c) monthly and (d) annual scales.

YLC region is 0.95 and 0.96 for the monthly streamflow and approximately 0.94 and 0.96 for the yearly streamflow, in the calibration and the validation period, respectively. In the MXC region, the correlation coefficient is 0.90 and 0.94 for the monthly streamflow and approximately 0.91 and 0.96 for the yearly streamflow, in the calibration and the validation periods, respectively. The NSE in the YLC region is 0.91 and 0.90 for the monthly streamflow and approximately 0.88 and 0.76 for the yearly streamflow, in the calibration and the validation periods, respectively. In the MXC region, the NSE are 0.85 and 0.74 for the monthly streamflow and approximately 0.80 and 0.78 for the yearly streamflow during the calibration and the validation periods, respectively. Although for the both watersheds the performance of the SWAT model during the validation period is found to be less accurate compared to the calibration period and the monthly performance generally better than the yearly results, the results of the performance are still considered satisfactory, which indicates that the fundamental rainfall-runoff relationship and water balances including the intra-annual distribution are well captured. We thus aver that these results are within the range of "the very good performance" benchmarks [42].

4.2. Characteristics of Land Use/Cover Changes. In order to investigate the change in land use from 1980 to 2010, we integrated the different sources of land use conducts in 1980s and 2000s and compared the fraction of main land use in two time slices from 1980s to 2000s. Figure 5 shows the fraction of land use in YLC and MXC regions. The land use structure shows slight changes from 1980s to 2000s. Pasture is the dominate land use pattern, occupying about $52 \%$ and $61 \%$ of total area of YLC and MXC, respectively, followed by barren land and forest land, occupying $23 \%$ and $22 \%$ of total YLC, and forest land and farm land, occupying $27 \%$ and $7 \%$ of total 


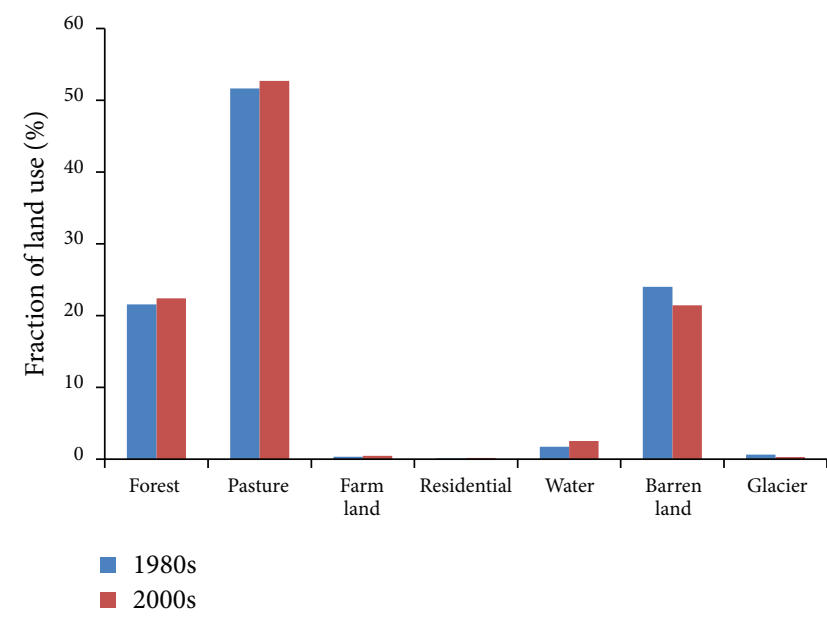

(a)

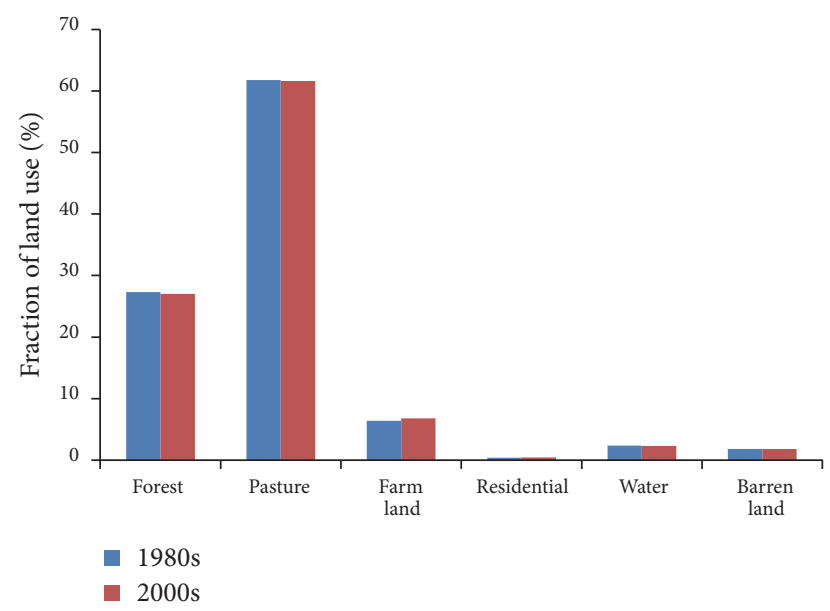

(b)

FIGURE 5: Fraction of land uses in YLC (a) and MXC (b) from 1980s to 2000s.

MXC, respectively. The other land use types occupy less than $2.5 \%$, which have limited effects on the runoff regimes.

Figure 6 shows the spatial distribution of land use conversion in the YLC and MXC regions. There are approximately $331 \mathrm{~km}^{2}$ in YLC and $176 \mathrm{~km}^{2}$ in MXC region that have changed their land use types occupying about 3.3\% and $1.2 \%$ of their entire catchment that underwent type conversions, respectively. We mainly focus on the land use conversions that occupied large areas and may lead to significant change in runoff regimes. In the YLC region, the forest increased mainly due to the conversion from the pasture $\left(63.65 \mathrm{~km}^{2}\right)$, which is primarily attributed to the afforestation programs and ecological environment restoration programs in Qilian mountain launched in early 2000s [43]. Pasture area increased results from the conversion from barren land $\left(226.03 \mathrm{~km}^{2}\right)$, which is due to the global warming that led to pasture extending to higher altitude area [33]. The other two conversion types in YLC are pasture to farm land $\left(13.3 \mathrm{~km}^{2}\right)$ and glacier to barren land $\left(28.37 \mathrm{~km}^{2}\right)$, which occupies about $12 \%$ of total land use conversion area. The conversions of land use indicate the increase of vegetation dynamics in the YLC region, which may lead to increase in canopy interception and transpiration through vegetation, meanwhile decreasing streamflow. In the MXC region, the three main conversion types are forest to pasture $\left(34.44 \mathrm{~km}^{2}\right)$, pasture to farmland $\left(92.37 \mathrm{~km}^{2}\right)$, and farmland to pasture $\left(37.23 \mathrm{~km}^{2}\right.$ ) (Figure $6(\mathrm{~b})$ ). The forest conversion to pasture mainly occurred due to deforestation at three forest farms. The conversion of pasture to farmland is the largest land use conversion type in the MXC region, which, due to herdsmen, has settled down and grasslands are reclaimed [44]. The conversion of farmland to pasture mainly results from grain for green program implemented in early 2000s in loess area of low stream [34]. The other three conversion types occupy small area: forest to farmland $\left(3.26 \mathrm{~km}^{2}\right)$, pasture to residential $\left(3.59 \mathrm{~km}^{2}\right)$, and farmland to residential $\left(5.89 \mathrm{~km}^{2}\right)$. These conversions are relevant to urbanization and reclamation. From the analysis above, we can conclude that the climate change influences the land use conversion in the YLC region, and human activities influence the land use conversion in the MXC region over the 30 years.

4.3. Observed Changes in Precipitation, Air Temperature, and Streamflow. Figure 7 shows the yearly variation of precipitation, streamflow, and air temperature in the YLC region and MXC for the entire modeling period as well as a linear fitted to the observed values. Similar changes of these elements occurred in the two watersheds. The trends of precipitation and runoff decrease from 1980 to 1995 and increase from 1996 to 2010 in both watersheds. However these decrease or increase trends in YLC are slighter than that in MXC. This indicates that variation of water vapor sources due to climate change is more obvious in MXC than in YLC. This is mainly because the Asia summer monsoon tends to affect the MXC region more significantly than the YLC region resulting in more water vapor received in MXC than YLC region [22]. However, the results of precipitation and streamflow trend magnitudes did not pass the significance test of 0.05 , except for the streamflow in the MXC region during the period 1980-1995. The increasing trend of air temperature in the YLC region is more obvious than in the MXC region with rate of $0.0381^{\circ} \mathrm{C} / \mathrm{a}(p<0.05)$ in the YLC compared to $0.0265^{\circ} \mathrm{C} / \mathrm{a}(p<0.05)$ in the MXC region from 1980 to 1995. It is important to note that the significant increasing of air temperature magnitude means significant effects on the watershed evapotranspiration. From the difference of the change rates between precipitation and runoff, we can find that evapotranspiration in YLC is not intensive compared to that in MXC. Based on the above analysis, it is evident that the precipitation and streamflow have changed to a notable extent around 1995 and 1996. In accordance with this, we divided the period 1980-1995 as baseline phase and the period 1996-2010 as the affection phase in our study.

4.4. Effects of Climate Change and LUCC on Streamflow Regimes. Table 3 shows the results of streamflow simulated by the SWAT model under the four hypothetical scenarios 
TABLE 3: Simulated annual runoff for different climate and land uses scenarios in YLC and MXC (mm). Delta $Q_{C}=$ average of $(S 3-S 1)+$ $(S 4-S 2)$, delta $Q_{L}=$ average of $(S 2-S 1)+(S 4-S 3)$, and the total change delta $Q=(S 4-S 1)$. Percent\% delta $Q_{C}=\operatorname{delta} Q C /$ delta $Q \times 100$. Percent $\%$ delta $Q_{L}=\operatorname{delta} Q L /$ delta $Q \times 100$.

\begin{tabular}{|c|c|c|c|c|c|c|c|c|}
\hline Watersheds & Scenarios & Climate & LUCC & Precipitation & Runoff & & \multicolumn{2}{|c|}{ Runoff change } \\
\hline \multirow{4}{*}{ YLC } & $(S 1)$ & 1982-1995 & $1980 \mathrm{~s}$ & 460.1 & 176.3 & & & Percent, \% \\
\hline & $(S 2)$ & 1982-1995 & $2000 s$ & 460.1 & 176.5 & $\Delta Q_{C}$ & 6.0 & 107.30 \\
\hline & $(S 3)$ & $1996-2010$ & $1980 s$ & 482.6 & 182.9 & $\Delta Q_{L}$ & -0.4 & -7.30 \\
\hline & $(S 4)$ & $1996-2010$ & $2000 \mathrm{~s}$ & 482.6 & 181.9 & $\Delta \mathrm{Q}$ & 5.6 & 100 \\
\hline \multirow{4}{*}{ MXC } & $(S 1)$ & 1982-1995 & $1980 \mathrm{~s}$ & 591.7 & 186.9 & & & \\
\hline & $(S 2)$ & 1982-1995 & $2000 \mathrm{~s}$ & 591.7 & 186.6 & $\Delta Q_{C}$ & -7.5 & -93.75 \\
\hline & $(S 3)$ & $1996-2010$ & $1980 \mathrm{~s}$ & 588.4 & 179.6 & $\Delta Q_{L}$ & -0.5 & -6.25 \\
\hline & $(S 4)$ & $1996-2010$ & $2000 s$ & 588.4 & 178.9 & $\Delta Q$ & -8.0 & 100 \\
\hline
\end{tabular}

as presented in Section 3.3. Compared to $(S 1)$, the simulated average annual runoff in $S 4$ appeared to increase by approximately $5.6 \mathrm{~mm}$ in the YLC region and appeared to decrease by approximately $8.0 \mathrm{~mm}$ in the MXC region. These changes consequently result in, respectively, $3.1 \%$ and $4.3 \%$ of their total streamflow changes. It represents the combination of climate and land use change effects during the period 1980 to 2000 in the two watersheds. The difference between (S1) and (S2) and between (S3) and (S4) shows the influence of land use change during the two subject periods. The separation equation (3) is used to assess the impact of land use change. The results also suggest that the land use change leads to a decrease in average streamflow by approximately $0.4 \mathrm{~mm}$ and $0.5 \mathrm{~mm}$, which then accounts for approximately $7.30 \%$ and $6.25 \%$ of the annual average streamflow changes in the YLC and MXC regions. The influence of climate change in the two periods can be calculated by the difference between $(S 1)$ and (S3) and between (S2) and (S4). The climate variation increases streamflow by $6 \mathrm{~mm}$, which accounts for about $107.30 \%$ of total streamflow change in the YLC region and a decrease in streamflow by approximately $7.5 \mathrm{~mm}$, which accounts for approximately $93.75 \%$ of total streamflow change in the MXC region. This indicates that the climate change shows opposite effects on streamflow and the impact of climate exceeds by far that of LUCC in two studied watersheds.

4.4.1. Effects of LUCC on Flow Regimes. In this paper, the simulated results instead of the measured data are used to compare hydrological model outcomes. The flow duration curve (FDC) is applied to the monthly stream flow to further quantify the temporal variation of the hydrological regimes. Flow duration curves are considered as a simple yet comprehensive approach to stream flow analysis that gives a graphical view of the overall variability associated with stream flow over a period of time [16]. Flow duration curves for the YLC and the MXC region are shown in Figure 8 with different time slices. The contrast between (S1) and (S2) and between (S3) and (S4) shows the influence of land use change in the two study periods. From Figures $8(\mathrm{a})$ and $8(\mathrm{~b})$, we can see the differences between the two land use situations in the YLC region. The curves for the land use situation within 2000s are almost under the below of the curves for the land use situation of 1980s. This indicates that the LUCC leads to a decrease in monthly stream flow in the YLC region although the decreasing effects are very small. Figures $8(\mathrm{c})$ and $8(\mathrm{~d})$ present the differences of LUCC impacts on the flow duration curve in the MXC region. Evidently, the two curves for the land use situation of 1980s and 2000s are almost overlapped. This means the LUCC impacts on the stream flow in MXC are almost negligible. Based on the above analysis, it is evident that the LUCC has limited impacts on flow regimes in both watersheds, primarily attributable to the area of land use changes that are small compared to entire watershed area.

\subsubsection{Effects of Climate Change on Flow Regimes. Figure 9} presents the climate change impacts on stream flow under different land use situation in two catchments. The curves for two slices are intertwined in each land use situations and respective catchments. This reflects the uncertainty and complexity of the climate variation within these regions. Compared to the impacts of LUCC, climate change impacts on the stream flow are more clear, indicating that the influences of climate factor on streamflow are predominant in these two study catchments. However, the impacts of climate change and LUCC on stream flow are various in different phases of flow duration curve. Thus, we selected six representative streamflow regime metrics to identify the separate impacts of climate change and LUCC on stream flow in two watersheds.

Due to the combined climate and land use change influences, the six flow regimes appear to have changed accordingly. From Table 4, we can see that climate change leads to all streamflow metrics increasing in the YLC region, except for the decreasing of CvMF. This implies that climate change increases both the high-flow and low-flow, while the variation of streamflow is decreasing. In contrast, climate factors have an opposite influence on streamflow metrics in the MXC region. That is, climate has led to a decrease in all streamflow metrics, except the BFI, indicating that the climate change was able to induce a decrease in the high-flow, low-flow, and variation of streamflow. LUCC cause the MMF, Lw75, Hg25, and CvMF decrease and DMF and BFI increase in both two watersheds. These changes imply that LUCC can cause a decrease in the magnitudes and variations of streamflow while increasing the base flow. Meanwhile, climate change factor has larger contributions to all streamflow 

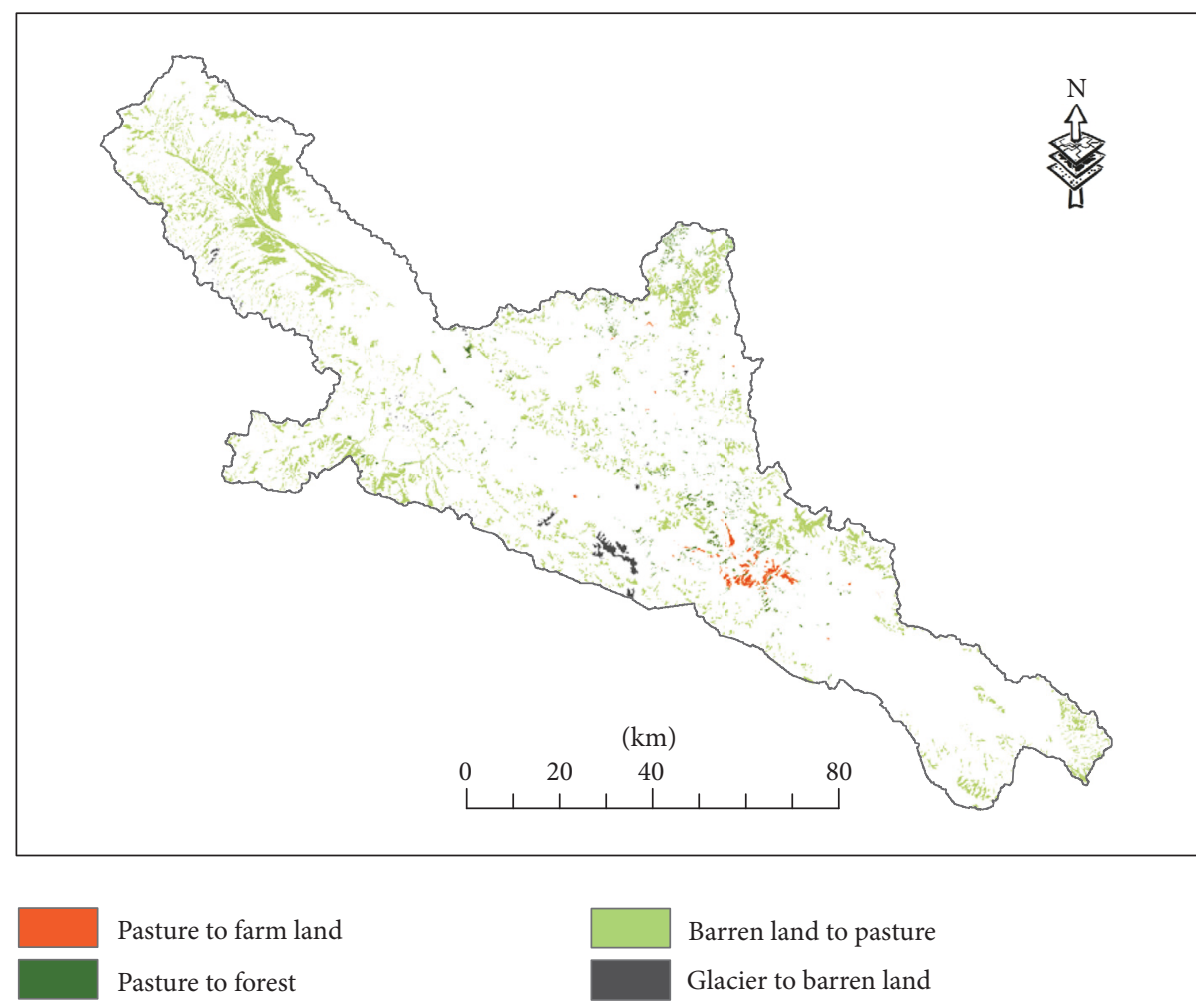

Barren land to pasture

Glacier to barren land

(a)

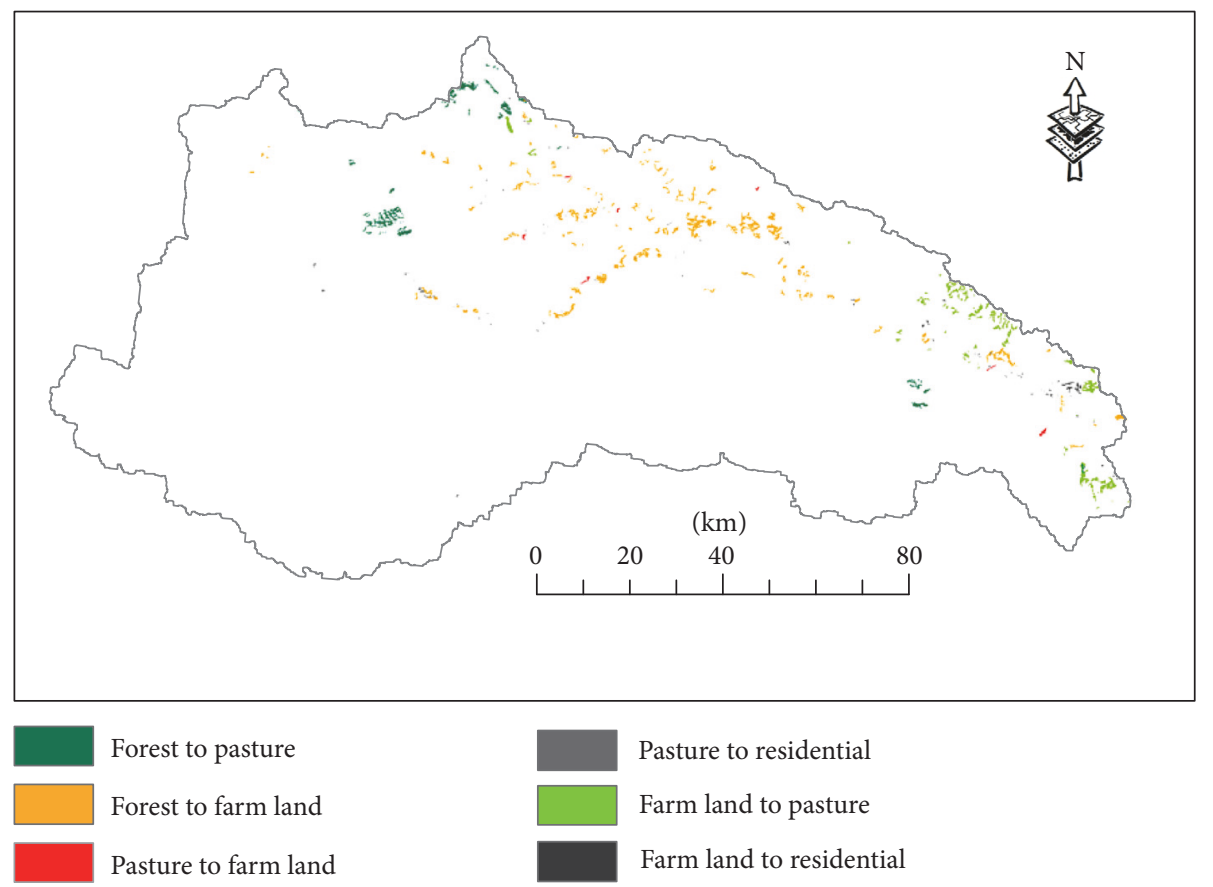

(b)

FIGURE 6: Spatial distribution of dominated land use conversion in YLC (a) and MXC (b).

metrics compared to LUCC in both watersheds. In accordance with this, we can conclude that all streamflow metrics have a larger contribution from climate change than LUCC, indicating that climate change is more relevant to a shift in the flow regimes. It can thus be averred that the contribution of climate change acts to dominate the change in flow regimes and the contribution of land use deduction is relatively small. 
TABLE 4: Separate contribution of climate change and LUCC on runoff regimes in YLC and MXC.

\begin{tabular}{|c|c|c|c|c|c|c|}
\hline & \multicolumn{3}{|c|}{ YLC } & \multicolumn{3}{|c|}{ MXC } \\
\hline & LU1980s & LU2000s & LU impact & LU1980s & LU2000s & LU impact \\
\hline \multicolumn{7}{|l|}{$\overline{\mathrm{MMF}}$} \\
\hline 1982-1995 & 176.3 & 176.5 & \multirow{2}{*}{$-7.14 \%$} & 186.9 & 186.6 & \multirow{2}{*}{$-6.25 \%$} \\
\hline 1996-2010 & 182.9 & 181.9 & & 179.6 & 178.9 & \\
\hline CC impact & \multicolumn{2}{|c|}{$107.14 \%$} & \multicolumn{4}{|c|}{$-93.75 \%$} \\
\hline \multicolumn{7}{|l|}{ Lw75 } \\
\hline 1982-1995 & 4.05 & 4.02 & \multirow{2}{*}{$-6.25 \%$} & 6.96 & 6.95 & \multirow{2}{*}{$-19.20 \%$} \\
\hline 1996-2010 & 4.38 & 4.37 & & 6.92 & 6.91 & \\
\hline CC impact & \multicolumn{2}{|c|}{$106.25 \%$} & \multicolumn{4}{|c|}{$-80.80 \%$} \\
\hline \multicolumn{7}{|l|}{ Hg25 } \\
\hline 1982-1995 & 22.31 & 22.29 & \multirow{2}{*}{$-16.67 \%$} & 20.4 & 20.51 & \multirow{2}{*}{$-2.08 \%$} \\
\hline 1996-2010 & 22.45 & 22.43 & & 20.28 & 20.16 & \\
\hline CC impact & \multicolumn{2}{|c|}{$116.67 \%$} & \multicolumn{4}{|c|}{$-97.92 \%$} \\
\hline \multicolumn{7}{|l|}{ CvMF } \\
\hline 1982-1995 & 0.959 & 0.931 & \multirow{2}{*}{$-30.39 \%$} & 0.653 & 0.652 & \multirow{2}{*}{$-2.97 \%$} \\
\hline 1996-2010 & 0.894 & 0.866 & & 0.628 & 0.628 & \\
\hline CC impact & \multicolumn{2}{|c|}{$-69.61 \%$} & \multicolumn{4}{|c|}{$-97.03 \%$} \\
\hline \multicolumn{7}{|l|}{ DMF } \\
\hline 1982-1995 & 0.467 & 0.497 & \multirow{2}{*}{$36.68 \%$} & 0.515 & 0.521 & \multirow{3}{*}{$24.79 \%$} \\
\hline 1996-2010 & 0.514 & 0.530 & & 0.486 & 0.492 & \\
\hline CC impact & & & & & & \\
\hline \multicolumn{7}{|l|}{ BFI } \\
\hline 1982-1995 & 0.227 & 0.236 & \multirow{2}{*}{$38.70 \%$} & 0.628 & 0.622 & \multirow{2}{*}{$45.80 \%$} \\
\hline 1996-2010 & 0.242 & 0.255 & & 0.621 & 0.616 & \\
\hline CC impact & \multicolumn{2}{|c|}{$61.30 \%$} & \multicolumn{4}{|c|}{$54.20 \%$} \\
\hline
\end{tabular}
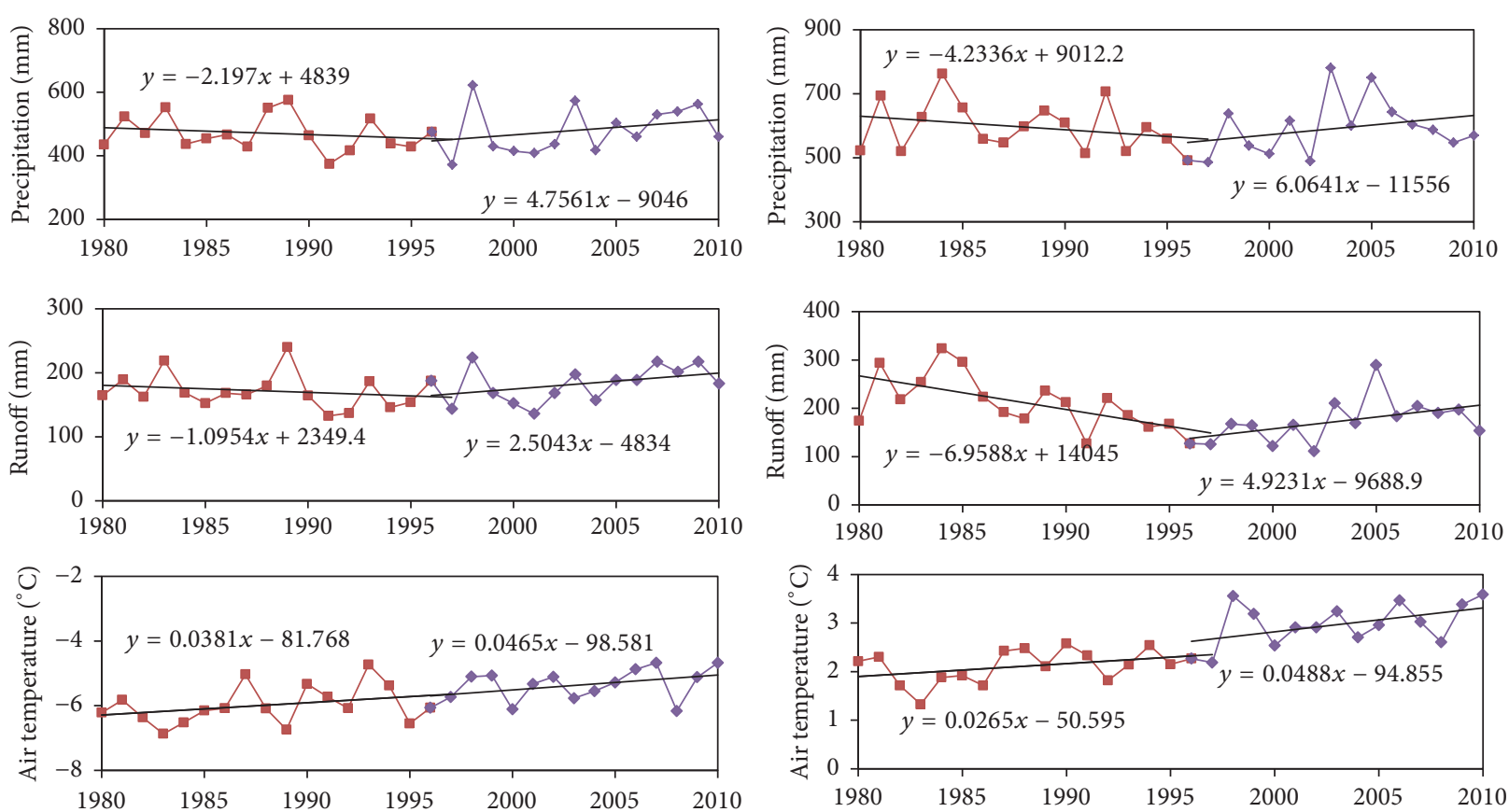

FIgURE 7: Temporal changes in precipitation, runoff, and temperature from 1980 to 2010, YLC to the left and MXC to the right.

This study attempted to disentangle the effects of climate change and LUCC on streamflow in two selected watersheds and to compare their different effects towards the dominant climate types and land cover conditions. In published literature, there have been some previous research works that have focused on the investigation of climate and land cover changes impacts [21, 26, 45-48]. The results of these studies agree with our study with the primary finding that climate change has influenced the streamflow regime more significantly than land use/cover change in the study 


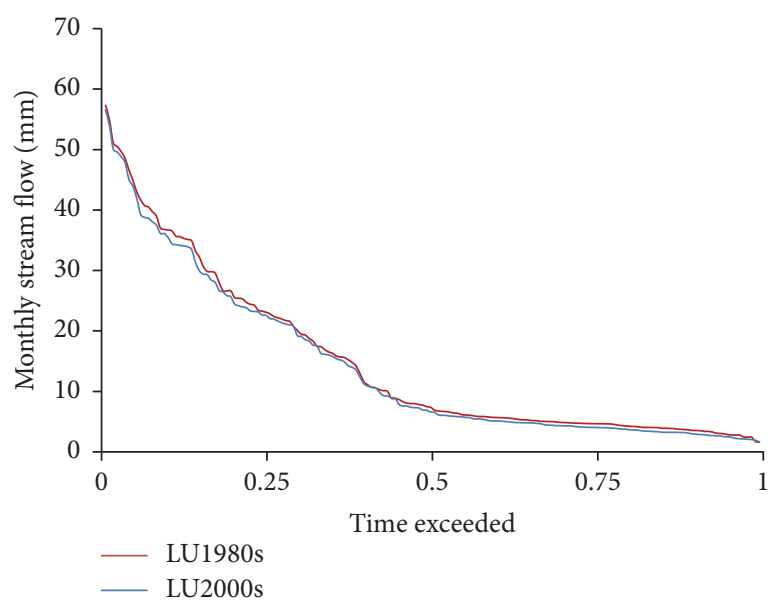

(a)

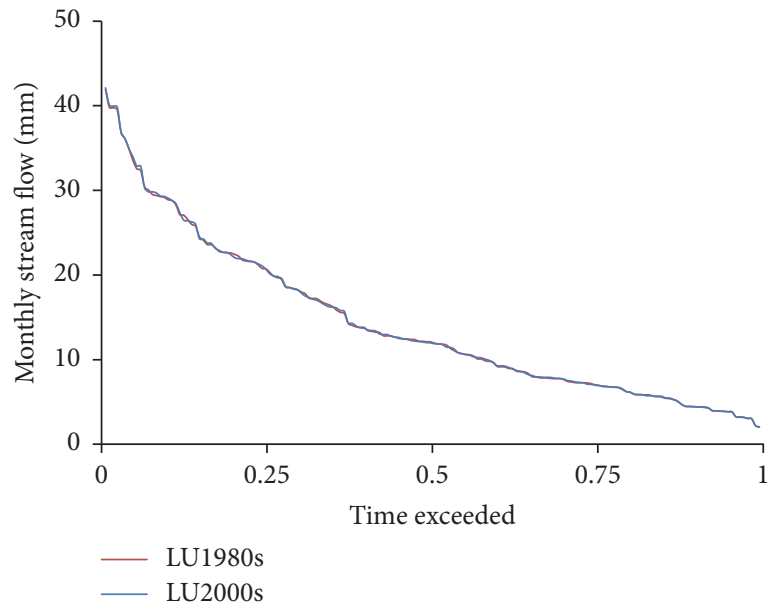

(c)

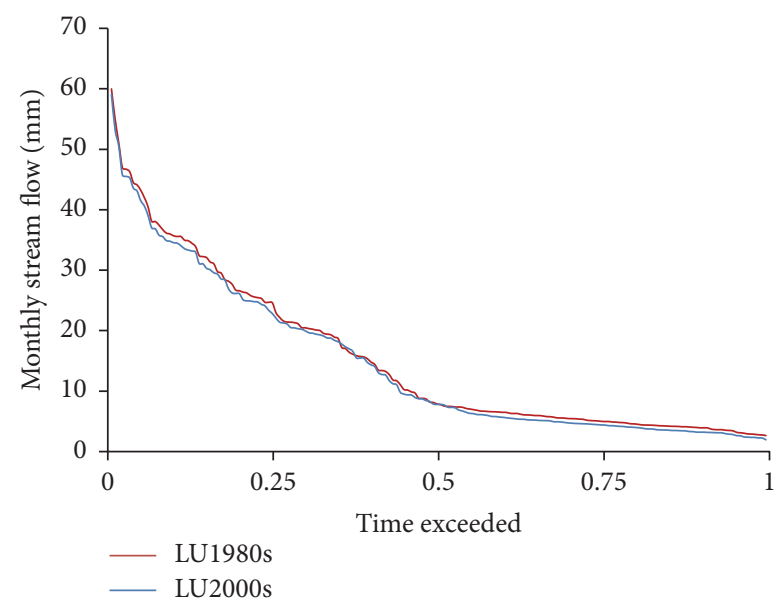

(b)

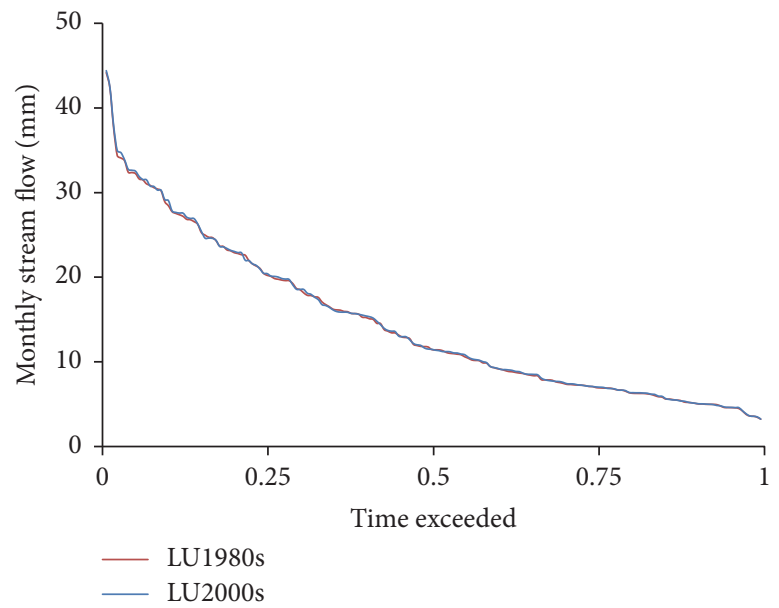

(d)

FIGURE 8: Impact of LUCC on flow duration curve in YLC in (a) 1982-1995 and (b) 1996-2010 and in MXC in (c) 1982-1995 and (d) 1996-2010.

regions $[21,48,49]$. It is worthwhile to note that our study also emphasize the impacts of climate and land use/cover change on flow regimes and the latitudinal effect of climate on streamflow regimes. The results of this study further confirmed that the climate change offers a dominative effect on the magnitude, variability, duration, and component of streamflow regimes.

\section{Conclusions}

Deficit of water resources in China has raised the importance of investigating the causality of hydrological processes changes. It is widely accepted that these processes are controlled mainly by climate conditions. Notwithstanding this, it is also believed that they are strongly influenced by LUCC. The latter effect is produced by anthropogenic activities, which, in part, are the causes of climate change. In the present study, the SWAT method is successfully applied to separate the climatic and land cover impacts on the flow regime changes in two watersheds of northeastern Tibetan Plateau. This study has confirmed the usefulness of SWAT model for separating the impacts of climate change compared to those from LUCC on flow regimes.

The integration of the effects of LUCC and climate change was seen to increase annual streamflow by $5.6 \mathrm{~mm}$ in the YLC region and a subsequent decrease of annual streamflow by $8.0 \mathrm{~mm}$ in the MXC region, of approximately $3.2 \%$ and $3.4 \%$ of the total streamflow, respectively. It was evident that climate change shows an opposite effect in two watersheds. The results showed that climate change is confirmed to outweigh the impacts of LUCC on streamflow, leading to an increase in streamflow in the YLC and a decline in the MXC region, measured as approximately $107.3 \%$ and $93.75 \%$ of the total streamflow changes, respectively. The LUCC influence showed changes of approximately $-7.3 \%$ and $6.25 \%$ of total runoff. These results outcomes were based on analysis of data collected over the last 30 years, showing that the climate change has significant impact compared to LUCC on flow regimes in the study region. Climate change is thus more relevant to shifting the flow regimes and can be seen to dominate the hydrological processes changes in northeast Tibetan Plateau. 


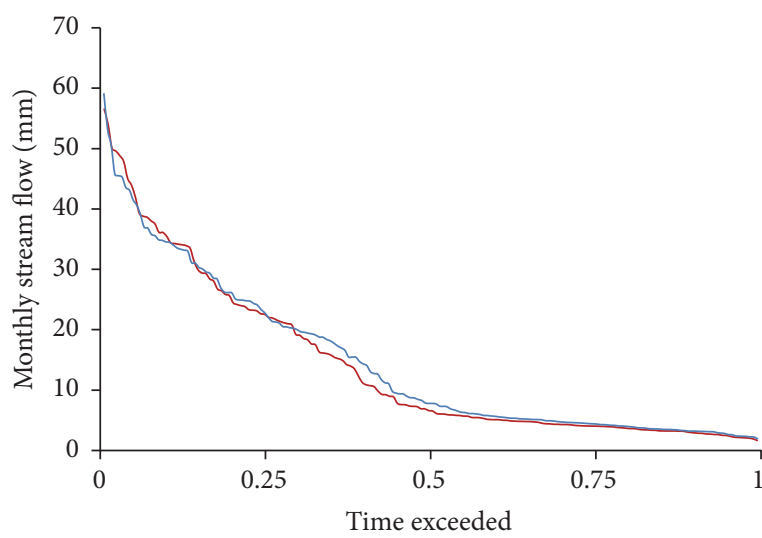

- 1982-1995

- 1996-2010

(a)

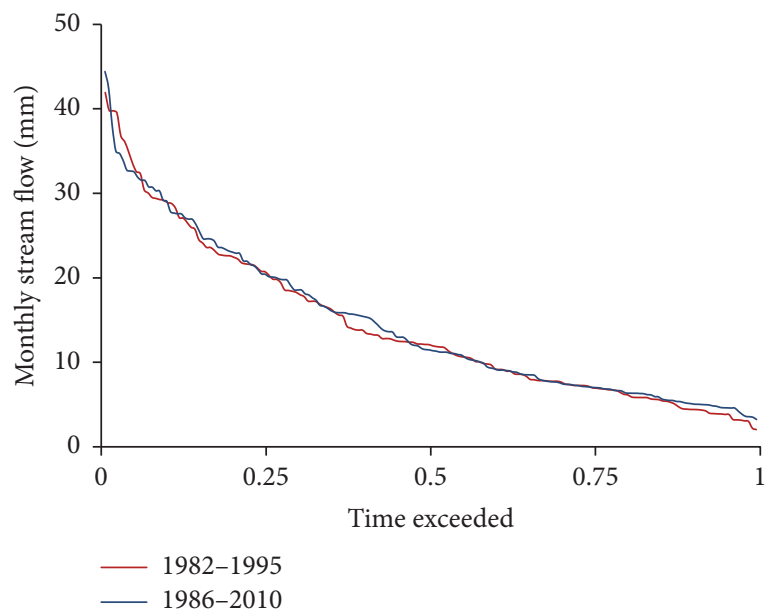

(c)

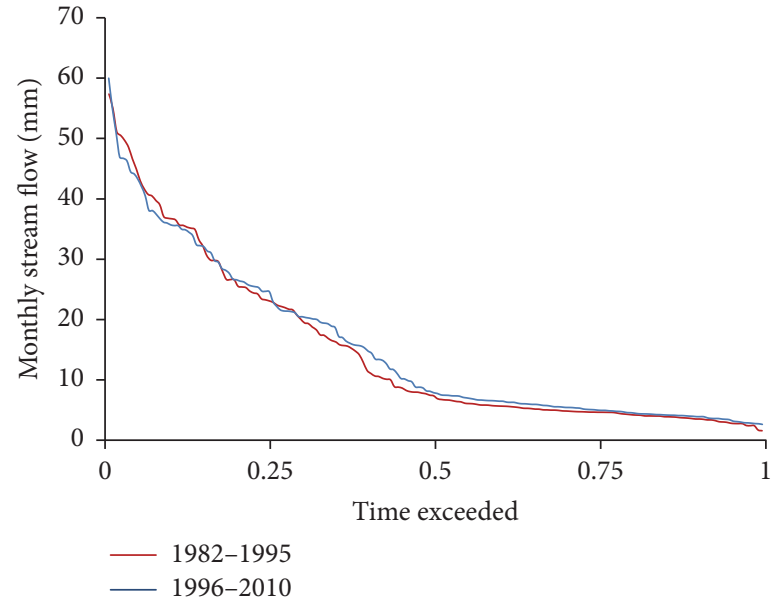

(b)

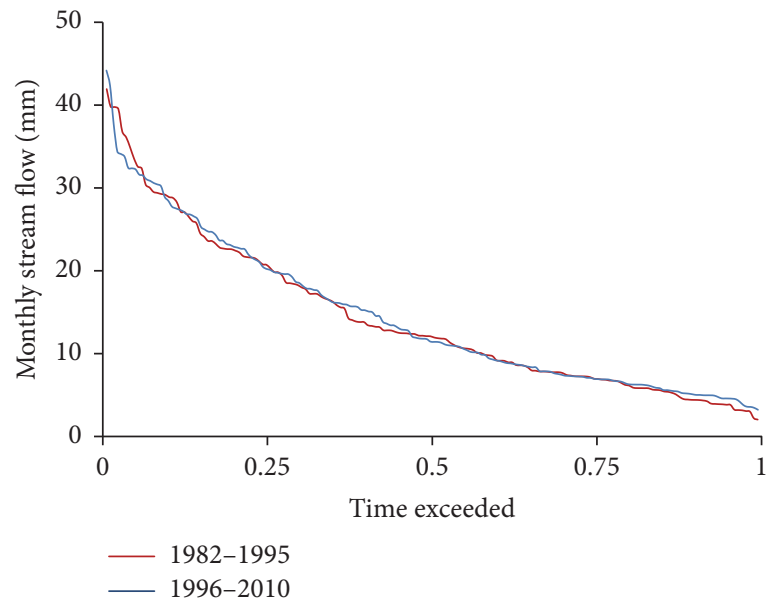

(d)

FIGURE 9: Impacts of climate change on flow duration curve in YLC for (a) LU1980s and (b) LU2000s and in MXC for (c) LU1980s and (d) LU2000s.

Evident from study, we conclude that it is critical to apply an integrated approach, which combines the effects of climate and LUCC, for an accurate assessment of flow regimes. Future investigations should thus address the projection of different environmental scenarios for the study area and also take into account the uncertainty inherent in predicting both climate change and LUCC.

\section{Conflicts of Interest}

The authors declare that there are no conflicts of interest regarding the publication of this paper.

\section{Acknowledgments}

This study was supported by National Key R\&D Program of China (2017YFC0404302, 2016YFC0400908), the Key Research Program of Frontier Sciences, CAS (QYZDJ-SSWDQC031), the National Natural Science Foundation of China Project (41601038), and the China Postdoctoral Science
Foundation (2015M572620). The authors thank the Scientific Data Center in Cold and Arid Regions and the China Meteorological Data Sharing Service System for providing the data.

\section{References}

[1] S. Piao, P. Ciais, Y. Huang et al., "The impacts of climate change on water resources and agriculture in China," Nature, vol. 467, no. 7311, pp. 43-51, 2010.

[2] X. Wei, W. Liu, and P. Zhou, "Quantifying the relative contributions of forest change and climatic variability to hydrology in large watersheds: a critical review of research methods," Water, vol. 5, no. 2, pp. 728-746, 2013.

[3] W. W. Immerzeel, L. P. H. Van Beek, and M. F. P. Bierkens, "Climate change will affect the asian water towers," Science, vol. 328, no. 5984, pp. 1382-1385, 2010.

[4] IPCC, Climate Change 2014: IPCC Fifth Assessment Synthesis Report-Summary for Policymakers-an Assessment of InterGovernmental Panel on Climate Change, Cambridge University Press, Cambridge, UK, 2014. 
[5] Z. Ye and Z. Li, "Spatiotemporal variability and trends of extreme precipitation in the huaihe river basin, a climatic transitional zone in East China," Advances in Meteorology, vol. 2017, Article ID 3197435, 15 pages, 2017.

[6] M. D. Tomer and K. E. Schilling, "A simple approach to distinguish land-use and climate-change effects on watershed hydrology," Journal of Hydrology, vol. 376, no. 1-2, pp. 24-33, 2009.

[7] X. Zhang, Y. Yamaguchi, F. Li, B. He, and Y. Chen, "Assessing the impacts of the 2009/2010 drought on vegetation indices, normalized difference water index, and land surface temperature in Southwestern China," Advances in Meteorology, vol. 2017, Article ID 6837493, 9 pages, 2017.

[8] L. G. Palamuleni, P. M. Ndomba, and H. J. Annegarn, "Evaluating land cover change and its impact on hydrological regime in Upper Shire river catchment, Malawi," Regional Environmental Change, vol. 11, no. 4, pp. 845-855, 2011.

[9] P. K. Panday, M. T. Coe, M. N. Macedo, P. Lefebvre, and A. D. D. A. Castanho, "Deforestation offsets water balance changes due to climate variability in the Xingu River in eastern Amazonia," Journal of Hydrology, vol. 523, pp. 822-829, 2015.

[10] C. Tague, G. Grant, M. Farrell, J. Choate, and A. Jefferson, “Deep groundwater mediates streamflow response to climate warming in the Oregon Cascades," Climatic Change, vol. 86, no. 1-2, pp. 189-210, 2008.

[11] H. Y. Li, Y. Q. Zhang, J. Vaze, and B. E. Wang, "Separating effects of vegetation change and climate variability using hydrological modelling and sensitivity-based approaches," Journal of Hydrology, vol. 420, pp. 403-418, 2012.

[12] Z. Hu, L. Wang, Z. Wang, Y. Hong, and H. Zheng, "Quantitative assessment of climate and human impacts on surface water resources in a typical semi-arid watershed in the middle reaches of the yellow river from 1985 to 2006," International Journal of Climatology, vol. 35, no. 1, pp. 97-113, 2015.

[13] J. Liu, C. Zhang, L. Kou, and Q. Zhou, "Effects of climate and land use changes on water resources in the Taoer river," Advances in Meteorology, vol. 2017, Article ID 1031854, 13 pages, 2017.

[14] C. Jothityangkoon, M. Sivapalan, and D. L. Farmer, "Process controls of water balance variability in a large semiarid catchment: Downward approach to hydrological model development," Journal of Hydrology, vol. 254, no. 1-4, pp. 174198, 2001.

[15] G. H. Leavesley, "Modeling the effects of climate change on water resources - A review," Climatic Change, vol. 28, no. 1-2, pp. 159-177, 1994.

[16] M. Natkhin, O. Dietrich, M. P. Schäfer, and G. Lischeid, "The effects of climate and changing land use on the discharge regime of a small catchment in Tanzania," Regional Environmental Change, vol. 15, no. 7, pp. 1269-1280, 2015.

[17] J. Chang, Y. Wang, E. Istanbulluoglu et al., "Impact of climate change and human activities on runoff in the Weihe River Basin, China," Quaternary International, vol. 380, pp. 169-179, 2015.

[18] I. B. Karlsson, T. O. Sonnenborg, J. C. Refsgaard et al., "Combined effects of climate models, hydrological model structures and land use scenarios on hydrological impacts of climate change," Journal of Hydrology, vol. 535, pp. 301-317, 2016.

[19] A. Zhao, X. Zhu, X. Liu, Y. Pan, and D. Zuo, "Impacts of land use change and climate variability on green and blue water resources in the Weihe River Basin of northwest China," CATENA, vol. 137, pp. 318-327, 2015.
[20] D. Legesse, C. Vallet-Coulomb, and F. Gasse, "Hydrological response of a catchment to climate and land use changes in Tropical Africa: case study south central Ethiopia," Journal of Hydrology, vol. 275, no. 1-2, pp. 67-85, 2003.

[21] L. Yang, Q. Feng, Z. Yin et al., "Identifying separate impacts of climate and land use/cover change on hydrological processes in upper stream of Heihe River, Northwest China," Hydrological Processes, vol. 31, no. 5, pp. 1100-1112, 2017.

[22] L. Zhu, X. Lü, J. Wang et al., "Climate change on the Tibetan Plateau in response to shifting atmospheric circulation since the LGM," Scientific Reports, vol. 5, 2015.

[23] K. Yang, H. Wu, J. Qin, C. Lin, W. Tang, and Y. Chen, "Recent climate changes over the Tibetan Plateau and their impacts on energy and water cycle: A review," Global and Planetary Change, vol. 112, pp. 79-91, 2014.

[24] A. Zhang, C. Zheng, S. Wang, and Y. Yao, "Analysis of streamflow variations in the Heihe River Basin, northwest China: trends, abrupt changes, driving factors and ecological influences," Journal of Hydrology: Regional Studies, vol. 3, pp. 106-124, 2015.

[25] Y. Zhang, G. Fu, B. Sun, S. Zhang, and B. Men, "Simulation and classification of the impacts of projected climate change on flow regimes in the arid Hexi Corridor of Northwest China," Journal of Geophysical Research Atmospheres, vol. 120, no. 15, pp. 74297453, 2015.

[26] Z. Yin, Q. Feng, S. Zou, and L. Yang, "Assessing variation in water balance components in mountainous Inland River Basin experiencing climate change," Water, vol. 8, no. 10, 472 pages, 2016.

[27] M. Xu, "Study on water storage change and its consideration in water balance in the mountain regions over arid Northwest China," Advances in Meteorology, vol. 2017, Article ID 4291765, 10 pages, 2017.

[28] L. Yang, Q. Feng, C. Li, J. Si, X. Wen, and Z. Yin, “Detecting climate variability impacts on reference and actual evapotranspiration in the Taohe River Basin, NW China," Hydrology Research, vol. 48, no. 2, pp. 596-612, 2017.

[29] Z. Yin, H. Xiao, S. Zou et al., "Simulation of hydrological processes of mountainous watersheds in inland river basins: taking the heihe mainstream river as an example," Journal of Arid Land, vol. 6, no. 1, pp. 16-26, 2014.

[30] Z. Li, Z. Xu, Q. Shao, and J. Yang, "Parameter estimation and uncertainty analysis of SWAT model in upper reaches of the Heihe river basin," Hydrological Processes, vol. 23, no. 19, pp. 2744-2753, 2009.

[31] U. Zhao and W. Zhang, "Rainfall-runoff simulation using the VIC-3L model over the Heihe river mountainous basin, China," in Proceedings of the 2005 IEEE International Geoscience and Remote Sensing Symposium, (IGARSS '05), pp. 4391-4394, IEEE, Seoul, South Korea, July 2005.

[32] Y. Liu, Z. An, H. W. Linderholm et al., "Annual temperatures during the last 2485 years in the mid-eastern tibetan plateau inferred from tree rings," Science in China, Series D: Earth Sciences, vol. 52, no. 3, pp. 348-359, 2009.

[33] Q. Feng, H. Ma, X. M. Jiang, X. Wang, and S. X. Cao, "Who and what caused desertification in China," Scientific Reports, vol. 5, Article ID 15998, 2015.

[34] C. B. Li, X. L. Zhang, J. G. Qi et al., "A case study of regional eco-hydrological characteristics in the Tao River Basin, northwestern China, based on evapotranspiration estimated by a coupled Budyko equation-crop coefficient approach," Science China Earth Sciences, vol. 58, no. 11, pp. 2103-2112, 2015. 
[35] B. D. Richter, J. V. Baumgartner, J. Powell, and D. P. Braun, "A method for assessing hydrologic alteration within ecosystems," Conservation Biology, vol. 10, no. 4, pp. 1163-1174, 1996.

[36] L. A. Alvarenga, C. R. de Mello, A. Colombo, L. A. Cuartas, and L. C. Bowling, "Assessment of land cover change on the hydrology of a Brazilian headwater watershed using the distributed hydrology-soil-vegetation model," Catena, vol. 143, pp. 7-17, 2016.

[37] J. G. Arnold, R. Srinivasan, R. S. Muttiah, and J. R. Williams, "Large area hydrologic modeling and assessment part I: model development," Journal of the American Water Resources Association, vol. 34, no. 1, pp. 73-89, 1998.

[38] J.-W. Jung, K.-S. Yoon, D.-H. Choi et al., "Water management practices and SCS curve numbers of paddy fields equipped with surface drainage pipes," Agricultural Water Management, vol. 110, pp. 78-83, 2012.

[39] X. Zhang, L. Zhang, J. Zhao, P. Rustomji, and P. Hairsine, "Responses of streamflow to changes in climate and land use/ cover in the Loess Plateau, China," Water Resources Research, vol. 44, no. 7, Article ID W00A07, 2008.

[40] W. Liu, X. Wei, S. Liu et al., "How do climate and forest changes affect long-term streamflow dynamics: a case study in the upper reach of poyang river basin," Ecohydrology, vol. 8, no. 1, pp. 4657, 2015.

[41] J. H. Lafontaine, L. E. Hay, R. J. Viger, R. S. Regan, and S. L. Markstrom, "Effects of climate and land cover on hydrology in the Southeastern U.S.: potential impacts on watershed planning," Journal of the American Water Resources Association, vol. 51, no. 5, pp. 1235-1261, 2015.

[42] D. N. Moriasi, J. G. Arnold, M. W. Van Liew, R. L. Bingner, R. D. Harmel, and T. L. Veith, "Model evaluation guidelines for systematic quantification of accuracy in watershed simulations," Transactions of the ASABE, vol. 50, no. 3, pp. 885-900, 2007.

[43] W. Liang, D. Bai, F. Wang et al., "Quantifying the impacts of climate change and ecological restoration on streamflow changes based on a Budyko hydrological model in China's Loess Plateau," Water Resources Research, vol. 51, no. 8, pp. 6500-6519, 2015.

[44] C. Li, J. Qi, L. Yang et al., "Regional vegetation dynamics and its response to climate change-A case study in the Tao River Basin in Northwestern China," Environmental Research Letters, vol. 9, no. 12, Article ID 125003, 2014.

[45] Y. F. Zhang, D. X. Guan, C. J. Jin, A. Z.Wang, J. B. Wu, and F. H. Yuan, "Analysis of impacts of climate variability and human activity on streamflow for a river basin in Northeast China," Journal of Hydrology, vol. 410, no. 3-4, pp. 239-247, 2011.

[46] L. Zhang, Z. Nan, Y. Xu, and S. Li, "Hydrological impacts of land use change and climate variability in the headwater region of the Heihe River Basin, northwest China," PLoS ONE, vol. 11, no. 6, Article ID e0158394, 2016.

[47] L. Zhang, Z. Nan, W. Yu, and Y. Ge, "Modeling land-use and land-cover change and hydrological responses under consistent Climate change scenarios in the Heihe River Basin, China," Water Resources Management, vol. 29, no. 13, pp. 4701-4717, 2015.

[48] A. Zhang, W. Liu, Z. Yin, G. Fu, and C. Zheng, "How will climate change affect the water availability in the Heihe River Basin, Northwest China?" Journal of Hydrometeorology, vol. 17, no. 5, pp. 1517-1542, 2016.
[49] F. Tian, Y. H. Lü, B. J. Fu et al., "Challenge of vegetation greening on water resources sustainability: insights from a modelingbased analysis in Northwest China," Hydrological Processes, vol. 31, no. 7, pp. 1469-1478, 2017. 

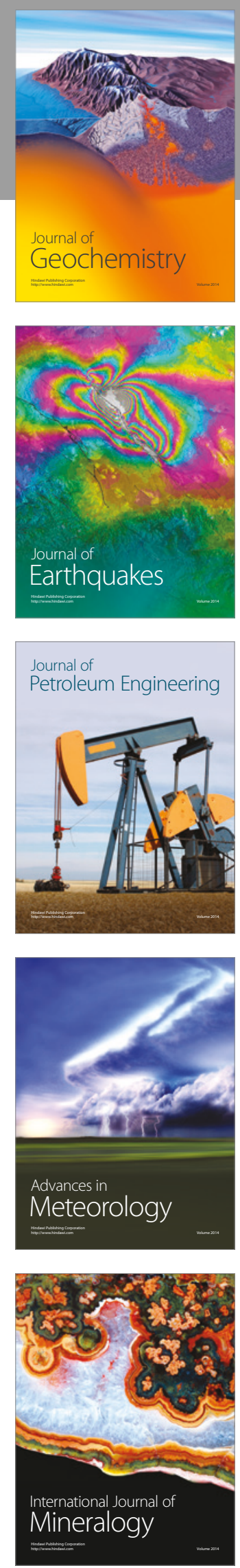
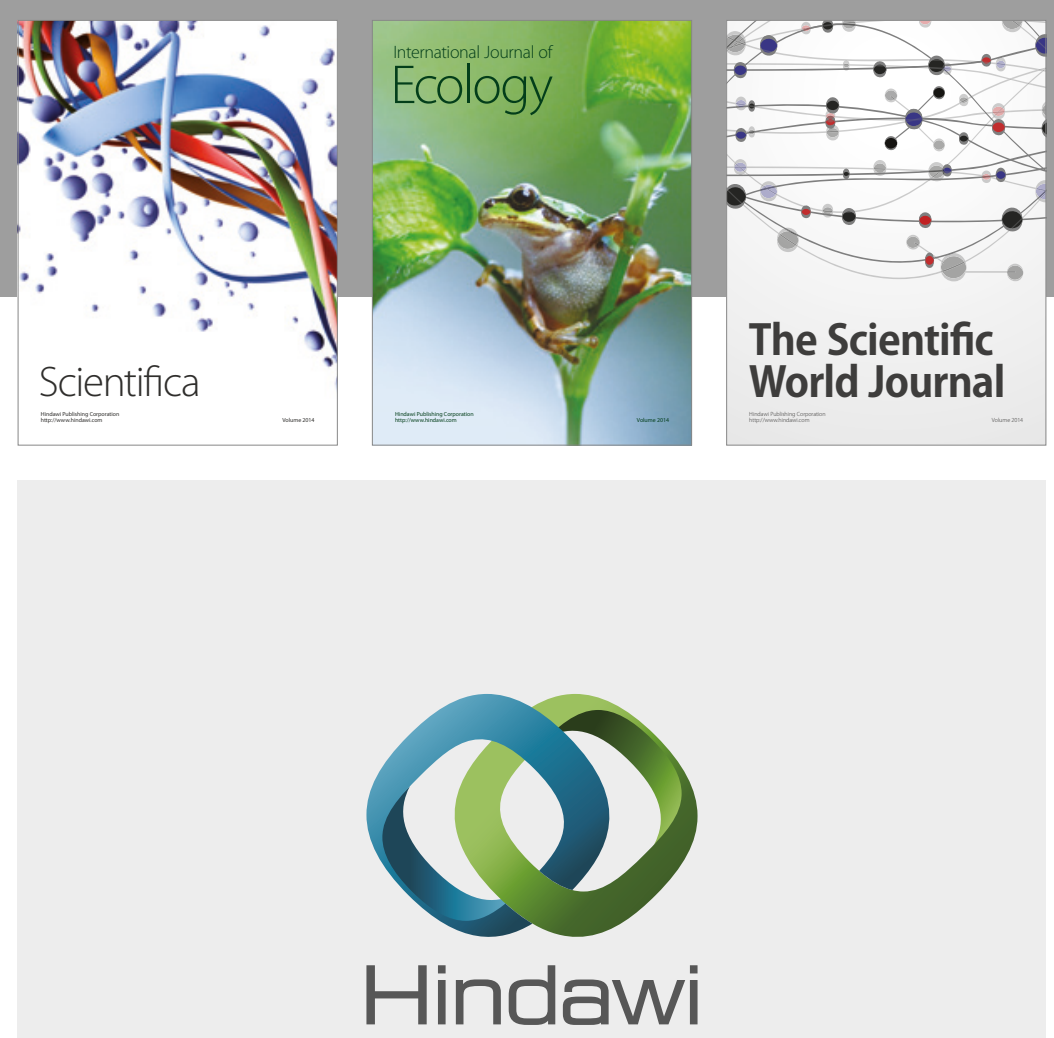

Submit your manuscripts at

https://www.hindawi.com
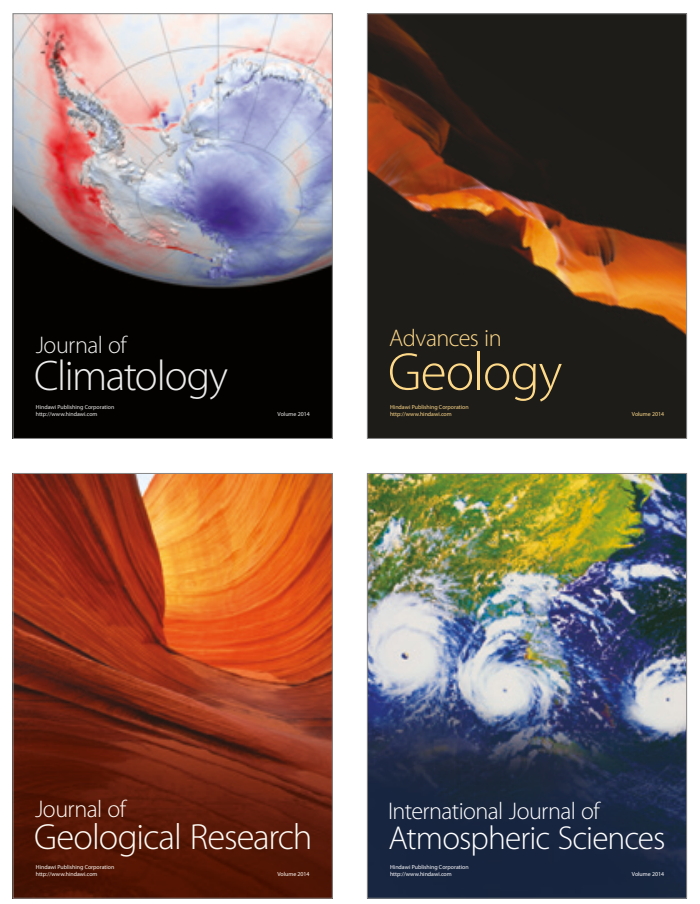

The Scientific

World Journal
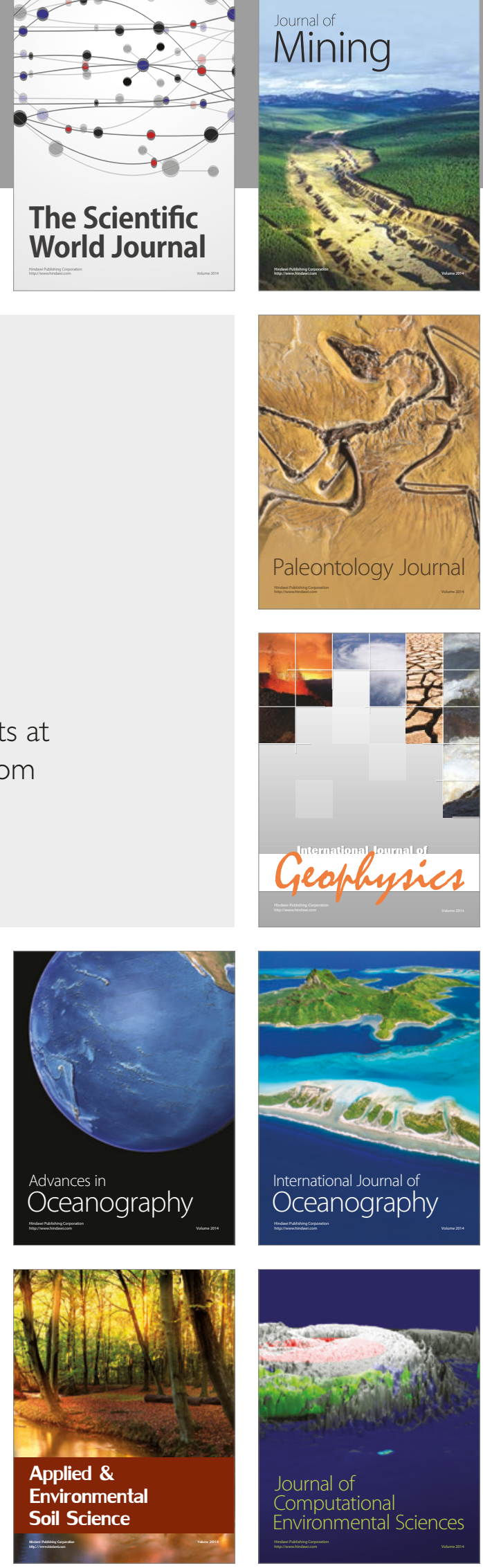